University of Nebraska - Lincoln

DigitalCommons@University of Nebraska - Lincoln

Faculty Publications: Department of Entomology

2019

Sublethal Effects of the Insecticide Pyrifluquinazon on the European Honey Bee (Hymenoptera: Apidae)

James M. Wilson

VirginiaTech, keepbees@vt.edu

Troy D. Anderson

University of Nebraska - Lincoln, tanderson44@unl.edu

Thomas P. Kuhar

VirginiaTech, tkuhar@vt.edu

Follow this and additional works at: https://digitalcommons.unl.edu/entomologyfacpub

Part of the Entomology Commons

Wilson, James M.; Anderson, Troy D.; and Kuhar, Thomas P., "Sublethal Effects of the Insecticide Pyrifluquinazon on the European Honey Bee (Hymenoptera: Apidae)" (2019). Faculty Publications: Department of Entomology. 827.

https://digitalcommons.unl.edu/entomologyfacpub/827

This Article is brought to you for free and open access by the Entomology, Department of at DigitalCommons@University of Nebraska - Lincoln. It has been accepted for inclusion in Faculty Publications: Department of Entomology by an authorized administrator of DigitalCommons@University of Nebraska - Lincoln. 


\title{
Sublethal Effects of the Insecticide Pyrifluquinazon on the European Honey Bee (Hymenoptera: Apidae)
}

\author{
James M. Wilson, ${ }^{1}$ Troy D. Anderson, ${ }^{2}$ and \\ Thomas P. Kuhar ${ }^{1}$ \\ 1 Department of Entomology, Virginia Tech, Blacksburg, VA 24060 \\ 2 Department of Entomology, University of Nebraska, \\ 103 Entomology Hall, Lincoln, NE 68583-0816 \\ Corresponding author — James M. Wilson, email keepbees@vt.edu \\ ORCID - J.M. Wilson http://orcid.org/0000-0001-9089-157X
}

\begin{abstract}
Pyrifluquinazon (PQZ) is an Insecticide Resistance Action Committee (IRAC) Group 9 insecticide that has recently been registered for use in the United States for control of soft-bodied sucking insect pests. Although it has been classified as practically nontoxic to honey bees, Apis mellifera L. (Hymenoptera: Apidae), based on acute contact bioassays, additional information on sublethal effects of this insecticide on honey bees is lacking. Using a combination of laboratory assays with video movement tracking software and near-field evaluations of colonies foraging in a hightunnel experiment, we determined that, when fed PQZ at a concentration of $84 \mathrm{mg}$ active ingredient (ai)/liter (= ppm) in sugar water, a reduction in overall movement by the foraging worker bees was observed. However, when provided with honey reserves in the hive, honey bees rejected the PQZ-treated sugar water. These results indicate that, if ingested at levels of $84 \mathrm{mg}$ ai/liter, PQZ could have a negative effect on honey bee behavior; however, honey bee workers appear to be able to detect the presence of PQZ in their food and reject it.
\end{abstract}

Keywords: qualifying risk, sublethal toxicity, honey bee pesticide exposure

Published in Journal of Economic Entomology, 112:3 (2019), pp 1050-1054.

doi: 10.1093/jee/toz014

Copyright (c) 2019 James M. Wilson, Troy D. Anderson, and Thomas P. Kuhar. Published by Oxford University Press on behalf of Entomological Society of America. Used by permission.

Submitted 20 September 2018; accepted 10 January 2019. 
Pyrifluquinazon (PQZ) is a relatively new insecticide belonging to IRAC Group 9: chordotonal organ transient receptor potential ion channel modulator (Nesterov et al. 2015), a limited group of pyridine azomethine derivatives (Sparks and Nauen 2015). PQZ has been found to be efficacious at controlling various soft-bodied sucking insects such as whiteflies, Bemisia spp. (Hemiptera: Aleyrodidae) (Palumbo 2013, McLeod and Rashid 2014), green peach aphid, Myzus persicae Sulzer (Hemiptera: Aphidae) (Kuhar et al. 2013), Gill's mealy bug, Ferrisia gilli Gullan (Hemiptera: Pseudococcidae) (Haviland and Rill 2015a), and citrus thrips, Scirtothrips citri Moulton (Thysanoptera: Thripidae) (Haviland and Rill 2015b), and soon will be registered in the United States on vegetable and fruit crops, many of which are insect-pollinated (USEPA 2018). As part of the eco-toxicological testing requirements of the U.S. Environmental Protection Agency (EPA) for pesticide registrations, acute contact toxicity bioassays showed that PQZ is 'practically non-toxic to honey bees' (USEPA 2012). In addition, an oral $\mathrm{LD}_{50}$ of $4.7 \mu \mathrm{g}$ of active ingredient per bee was submitted as part of the registration approval supplemental material for honey bee acute oral toxicity testing (USEPA 2012). However, beyond acute toxicity, there may still be sublethal risk associated with pesticide exposure to honey bees, which could negatively affect behavior and foraging ability as has been shown with other insecticides (Desneux et al. 2007). Observation of sublethal behavioral changes in feeding bees can be difficult to quantify, but other classes of insecticides have been shown to impair learning in honey bees (El Hassani et al. 2008). Sublethal effects on pollinators may have larger effects on their pollination services and colony health. We hypothesized that when exposed to PQZ-treated sources of sugar, honey bees will be able to detect and avoid exposing themselves to the toxicant. Herein, we describe further investigations into potential sublethal (behavioral) effects of PQZ on honey bees at laboratory and near-field scale experimental levels. 


\section{Methods and Materials}

\section{Laboratory Experiments}

Here, we adapted the techniques of Teeters et al. (2012) and Ingram et al. (2015) and used a video camera and movement tracking software to assess the behavioral response of honey bees exposed to PQZ. Approximately 40 foraging honey bees were collected from a hive located at the Virginia Tech Apiary near Blacksburg, VA. The hive was managed without miticides or other pesticides. Collected bees were maintained in a $9 \times 9 \times 7-\mathrm{cm}$ container at $32^{\circ} \mathrm{C}$ and $70 \% \mathrm{RH}$ for 12 $h$ in a Percival Scientific growth chamber without food to ensure that bees would exhibit adequate feeding behavior upon the introduction of a food source.

Bees were anesthetized using carbon dioxide gas and 32 bees were selected at random from the group. Bees were placed in 16 different Petri dishes $(9.5-\mathrm{cm}$ diam.) that were divided in half by a small segment of fiberglass window screen so that two bees occupied each dish, one on each side of the mesh as per Teeters et al. (2012). Each half of the dish contained a $0.5 \times 0.5 \times 1-\mathrm{cm}$ sugar agarose cube that was designated as a feeding zone. Dishes in the treatment column contained two such cubes that were mixed with the field rate solution of insecticide (84 mg/liter ai of PQZ; SePRO Corporation 2018) before the cube solidified. Formulated product was acquired from Nichino America, Inc., Wilmington, DE. Agarose cubes were positioned at the opposite sides of each dish at the maximum distance apart. Petri dishes that were in the control column only contained the sugar agarose cubes. A light table that was backlit using red LED light strips (620-nm wavelength) was used to provide illumination for the experimental recording, whereas external light was excluded by covering the recording camera and light box in black plastic (Larson and Anderson 2017). Petri dishes were arranged in four side-by-side columns of four dishes each so that each column contained one treatment, control, or PQZ-treated agarose cubes.

The movements by the 32 bees were recorded simultaneously using a Basler monochrome camera suspended above the 16 Petri dishes. Movement tracks of the bees were captured using Noldus EthoVision software program, EthovisionXT (Ver. 10; Noldus Information 
Technology, Inc., Leesburg, VA) over a 120 min recording duration at a capture rate of 30 samples per second. Using the EthoVision software, total distance moved $(\mathrm{cm})$, velocity $(\mathrm{cm} / \mathrm{s})$, and time $(\mathrm{s})$ spent in the feeding zone were measured and analyzed for each pair of bees. Data were analyzed using analysis of variance (ANOVA) in JMP (JMP Pro 14, SAS Institute, Cary, NC).

\section{Near-Field Evaluations of the Effect of PQZ on Honey Bee Foraging}

\section{Experimental Arena}

Adapting a design from Colin et al. (2004), we constructed two insect-proof high tunnels, each 22.0-m long, 7.9-m wide, and 3.7-m tall during the summer of 2014 and arranged south-southeast, so both tunnels received similar sunlight throughout the day at the Virginia Tech Price's Fork Research Station outside of Blacksburg, VA

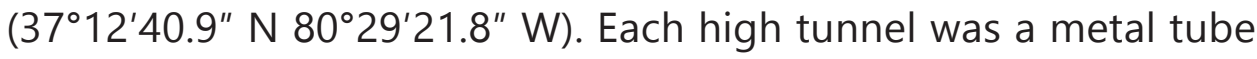
structure covered by 6 mil Clearspan plastic sheeting (FarmTek, Dyersville, IA), commonly used in growing season expansion high tunnel construction. The clear plastic is penetrable by the visible spectrum as well as UV light. The tunnels were used as near-field flight cages and allowed for free flight of the bees enclosed within them. Each high tunnel was divided in half by an opaque divider (the same as the ends) so that four flight arenas were created, the length of which allowed for colonies and feeders to be $10 \mathrm{~m}$ apart within each chamber. Floors were made of gravel that was kept free of weeds.

\section{Experimental Hives}

Colonies of honey bees were contained within a five-frame, full depth, nucleus hive box containing a laying queen and her progeny as well as frames of capped and uncapped brood, eggs, bee bread, and honey stores. One such colony is considered a nucleus colony referred to hereafter as a 'nuc'. The nucs were moved into the experimental chambers at night after dusk when all foragers returned to the hive, being sure to move the bees from an offsite location. Beginning with the initial hive introduction, each chamber was equipped with a shallow source of fresh water. Nucs were inspected on day 0 to ensure that colony provisions were adequate and egg laying was 
still ongoing. Each of the nucs was provisioned with $50 \mathrm{~g}$ of a pollen patty (Mann Lake Ltd., Hackensack, MN) at their introduction to the experimental chamber and replaced if needed during their pretreatment inspection.

\section{Honey Bee Training to a Feeder}

The morning after the introduction of the nucs, the water source was removed and replaced with a feeder containing a mix of a 50:50 (sucrose: water) solution, using cane sugar (Kroger Co., Cincinnati, $\mathrm{OH})$. The feeding apparatus was introduced to the chamber and placed directly in front of the nuc entrance. Feeders were blue, an easily distinguishable flower color, which would be attractive to foraging bees (Frisch 1950). Once bees began to feed, the feeder was moved $5 \mathrm{~m}$ away from the entrance initially, and finally, $10 \mathrm{~m}$ away by the afternoon of the second day if sufficient number of bees were attending and returning to the feeder. During the summers of 2015 and 2016, 10 nucs of honey bees were trained to feed from feeders containing a 50:50 water: sucrose solution over the course of $2 \mathrm{~d}$. The bees were then trained to locate the feeder during a fixed 2 - $h$ period for the next $2 \mathrm{~d}$. One hour after the scheduled removal of feeders, a source of water was given and subsequently removed $1 \mathrm{~h}$ before the next feeding event. Feeders were replaced with a water source before dusk each day. The third day of training began with only water, which was removed $1 \mathrm{~h}$ before the target feeding time of 10:00 am EST. Honey bees are most accurate in returning to artificial feeders in the early part of a photophase, and as such, we chose the target time above (Moore et al. 1989). Feeders were then introduced at the desired time point and removed at the end of the designated exposure period. One hour after the exposure period concluded, the water source was replaced. This process mimics the ephemeral nectar reward that bees can associate with certain flowers and provided the experiment with a focused exposure period in which to collect foraging data (Moore et al. 1989). The fourth day of training showed a marked increase in the response of bees to the feeder in their final location and during their specific exposure periods. This sequence was carried out simultaneously with three chambers and three nucs twice during the 2015 field season and with four chambers and four nucs in the 2016 field season. 


\section{Exposure and Observation of Trained Bees}

Once bees had been adequately trained to both the feeders and feeding time, video recordings using Go Pro Hero 3+ Black Edition cameras (GoPro, San Mateo, CA) were begun on day 0 to record the bees that were at the feeder and those that were actively feeding. Recordings were analyzed at 5-min intervals during the peak recruitment and feeding period (50 $\mathrm{min}$ ) for bees that were actively feeding. The number of actively feeding bees relative to time was recorded as bees in 'attendance'. Chambers were randomly assigned treatments and their feeders were dosed with $84 \mathrm{mg}$ ai/liter of PQZ in treated sucrose solutions during the exposure times in days $1-4$. The control chambers were only given the 50:50 water: sucrose solution. Data from days 0 through 4 were analyzed as above where a multivariate analysis of variance was used to model a repeated measures ANOVA (JMP Pro 14, SAS Institute). After the repeated measure analysis, each day was analyzed using an ANOVA (JMP Pro 14, SAS Institute). All $5 \mathrm{~d}$ of the experiment constituted one experimental run. The 2015 field season allowed for two such runs to be conducted with a total of three control nucs and three PQZ-treated nucs. In 2016, one run with two control nucs and two PQZ-treated nucs was carried out.

\section{Results}

\section{Laboratory Experiments Using Movement Tracking Software}

Behavioral data from the laboratory assay consisted of the cumulative duration ( $\mathrm{s}$ ) in which the bees spent in the feeding zone, the velocity $(\mathrm{cm} / \mathrm{s})$ of bee movement in each arena, and the overall distance $(\mathrm{cm})$ moved by each bee by treatment. When comparing the 16 control bees with the 15 bees exposed to PQZ incorporated agarose cubes, there was a significant treatment effect on cumulative duration spent in the feeding zone, where control bees spent significantly more time in the feeding zone (Fig. 1; $F=4.6079$; $\mathrm{df}=1,29 ; P \leq 0.0403$ ). There were no significant treatment effects on total distance moved $(F=$ 3.2890; $\mathrm{df}=1,29 ; P>0.05)$ or average velocity of movements $(F=$ 0.9107; $\mathrm{df}=1,29 ; P>0.05)$. 


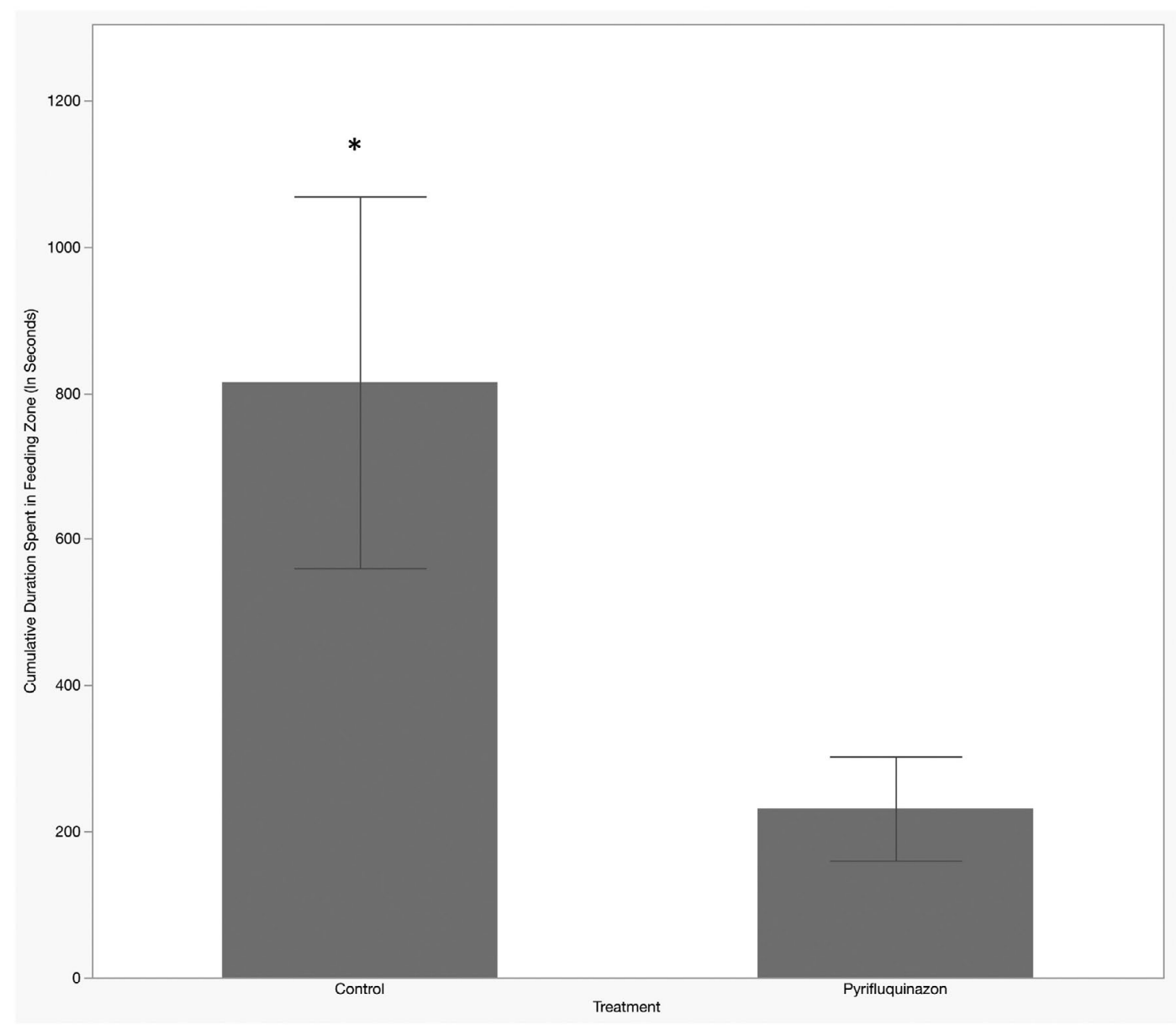

Fig. 1. Mean cumulative duration of bees in feeding zones by treatment (control agarose cubes or PQZ incorporated agarose cubes) in seconds from the laboratory evaluation of PQZ. Asterisk denotes statistical significance (Pooled $t$-test).

\section{Near-Field Evaluations of the Effect of PQZ on Honey Bee Foraging}

In the near-field dosing experiments, the change in the attendance at the feeder was apparent on all of the first days of dosing at PQZ incorporated sugar water feeders. Sphericity was not significant, whereas the time*treatment contrast was significantly different using a Greenhouse-Geiser correction ( $F=5.5569, \mathrm{df}=3,21 ; P \leq 0.0427)$. Days 0 
Table 1. Probabilities and degrees of freedom of treatment effect for days 1 through 4 of the near-field evaluations of the effect of PQZ on honey bee foraging

\begin{tabular}{lll} 
Day & $d f$ & Prob $>t$ \\
\hline 0 & 7 & 0.5402 NS \\
1 & 7 & 0.603 NS \\
2 & 7 & $0.0417^{*}$ \\
3 & 7 & $0.0164^{*}$ \\
4 & 7 & $0.0251^{*}$ \\
\hline
\end{tabular}

Asterisk denotes statistical significance (Pooled $t$-test).

and 1 showed no significant difference between treatments (Table 1). Days 2, 3, and 4 all had significantly different numbers of actively feeding bees in attendance at the control and PQZ incorporated sugar water feeders (Table 1, Fig. 2).

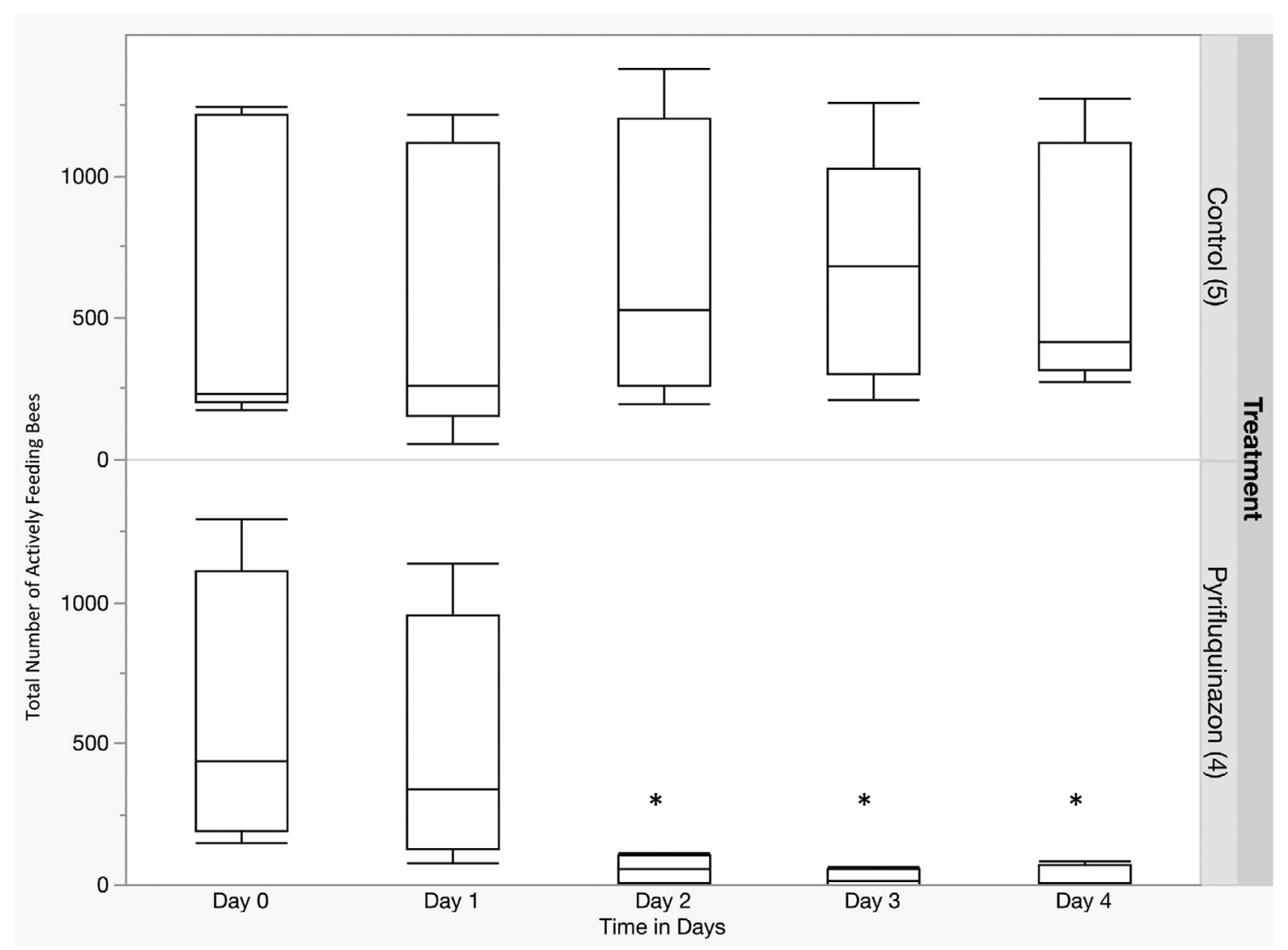

Fig. 2. Total number of bees actively feeding at sugar water provisioned feeders (Control) and PQZ incorporated sugar water feeders at 5 min recording intervals for each day of the experiment. Asterisk denotes statistical significance (Pooled $t$-test). 


\section{Discussion}

PQZ is a new selective insecticide in the process of being registered for use on various food crops in the United States (USEPA 2018). Although it has been classified as practically nontoxic to honey bees (USEPA 2012), further examination of sublethal insecticide dose effects on bee behavior could provide a more complete picture of the pesticide risk equation to pollinators. The relationship between sublethal exposure and pollinator functional behavior has not been clearly defined (Cresswell 2011). Recent exploration into field relevant exposure potential of honey bees to pesticides in the United States has highlighted that foraging bees likely encounter a large variety of pesticides as well as at various levels of toxicity (Pettis et al. 2013). Further research into the interactions that honey bees have with these toxicants in the environment may help to better qualify the risk that agricultural inputs may have on our pollinators. Monitoring sublethal effects of pesticides through behavior and interpreting the value of behavioral changes in honey bee foraging is challenging, some authors have chosen to create arenas that eliminate present observers in an effort to eliminate bias (Teeters et al. 2012, Ingram et al. 2015). We adopted those methods as an initial screening of the sublethal effects that PQZ may have on honey bees. In no-choice bioassays, we showed that bees fed on PQZ incorporated agarose cubes but spent significantly less time in the feeding zones compared with agarose cubes alone, whereas total distance moved and velocity of movement was not affected, suggesting a potential antifeedant response to the insecticide. Consequently, we employed a larger scaled assay conducted in high tunnels with video cameras to examine how colonies with foraging bees and honey reserves within their hive reacted to PQZ exposure. Near-field bee foraging experiments using insectproof high tunnels with video cameras have been previously used by Colin et al. (2004) in France to examine the change in honey bee foraging behavior after exposure to sublethal doses of imidacloprid and fipronil. This study was unique in its design and implementation, where the experimenters were able to isolate many extraneous factors and remove much of the observer bias and interference by using video cameras. The key to their study was quantifying foraging bee behavior in a way that could reflect changes in large numbers of bees to relate their activity levels to the abilities of the colony. We utilized 
a similar approach in an effort to characterize the risk to honey bee colonies from sublethal doses of PQZ. Because our experimental nucleus colonies were well provisioned with stores of honey, nectar and bee bread, the foraging bees from the colony could choose to feed from that source or to actively avoid it. We found that after $24 \mathrm{~h}$ of exposure to PQZ in their food, trained foraging bees began avoiding it, and by day 4 , virtually no bees fed on PQZ-treated food. This suggests learned behavior and avoidance. By further researching the sublethal behavioral effects that some insecticides have on bees, particularly in a colony, we can better qualify the risk. In this study, the avoidant behavior that honey bees exhibited to PQZ in their food could potentially limit the risk of this insecticide in the field.

\section{References}

Colin, M. E., J. M. Bonmatin, I. Moineau, C. Gaimon, S. Brun, and J. P. Vermandere. 2004. A method to quantify and analyze the foraging activity of honey bees: relevance to the sublethal effects induced by systemic insecticides. Arch. Environ. Contam. Toxicol. 47: 387-395.

Cresswell, J. E. 2011. A meta-analysis of experiments testing the effects of a neonicotinoid insecticide (imidacloprid) on honey bees. Ecotoxicology. 20: 149-157.

Desneux, N., A. Decourtye, and J. M. Delpuech. 2007. The sublethal effects of pesticides on beneficial arthropods. Annu. Rev. Entomol. 52: 81-106.

El Hassani, A. K., M. Dacher, V. Gary, M. Lambin, M. Gauthier, and C. Armengaud. 2008. Effects of sublethal doses of acetamiprid and thiamethoxam on the behavior of the honeybee (Apis mellifera). Arch. Environ. Contam. Toxicol. 54: 653-661.

von Frisch, K. 1950. Bees-their vision, chemical, senses and language. Cornell University Press, New York

Haviland, D. R., and S. M. Rill. 2015a. Ferrisia gilli control in Pistachio, 2015: Table 1. Arthrop. Manag. Tests 40: D6. doi:10.1093/amt/tsv031

Haviland, D. R., and S. M. Rill. 2015b. Citrus thrips control in southern highbush blueberries in California, 2014: Table 1. Arthrop. Manag. Tests 40(1): C11. doi:10.1093/amt/tsv021

Ingram, E. M., J. Augustin, M. D. Ellis, and B. D. Siegfried. 2015. Evaluating sublethal effects of orchard-applied pyrethroids using video-tracking software to quantify honey bee behaviors. Chemosphere. 135: 272-277.

Kuhar, T. P., H. Doughty, K. Kamminga, C. Philips, A. Wimer, and J. Aigner. 2013. Evaluation of insecticides for the control of green peach aphids in bell peppers in Virginia - 2012. Arthrop. Manag. Tests 38(1): E38. doi:10.4182/amt.2013.E38 
Larson, N. R., and T. D. Anderson. 2017. Video tracking protocol to screen deterrent chemistries for honey bees. J. Vis. Exp. (124): e55603. doi: $10.3791 / 55603$

McLeod, P., and T. Rashid. 2014. Toxicity of pyrifluquinazon against greenhouse whitefly on tomato produced in greenhouses. Adv. Entomol. 2: 115-119.

Moore, D., D. Siegfried, R. Wilson, and M. A. Rankin. 1989. The influence of time of day on the foraging behavior of the honeybee, Apis mellifera. J. Biol. Rhythms. 4: 305-325.

Nesterov, A., C. Spalthoff, R. Kandasamy, R. Katana, N. B. Rankl, M. Andrés, P. Jähde, J. A. Dorsch, L. F. Stam, F. J. Braun, et al. 2015. TRP channels in insect stretch receptors as insecticide targets. Neuron. 86: 665-671.

Palumbo, J. C. 2013. Evaluation of pyrifluquinazon for control of sweet potato whitefly in fall cantaloupes, 2012. Arthrop. Manag. Tests. 38(1): E18. doi:10.4182/amt.2013.E18

Pettis, J. S., E. M. Lichtenberg, M. Andree, J. Stitzinger, R. Rose, and D. Vanengelsdorp. 2013. Crop pollination exposes honey bees to pesticides which alters their susceptibility to the gut pathogen Nosema ceranae. PLoS One. 8: e70182.

SePRO Corporation, S. 2018. Rycar insecticide specimen label. Available from https://www.sepro.com/documents/Rycar_Label.pdf

Sparks, T. C., and R. Nauen. 2015. IRAC: Mode of action classification and insecticide resistance management. Pestic. Biochem. Physiol. 121: 122-128.

Teeters, B. S., R. M. Johnson, M. D. Ellis, and B. D. Siegfried. 2012. Using videotracking to assess sublethal effects of pesticides on honey bees (Apis mellifera L.). Environ. Toxicol. Chem. 31: 1349-1354.

U.S. Environmental Protection Agency. 2012. Ecological risk summary for the section 3 new chemical registration of pyrifluquinazon for indoor greenhouse use. Available from https://www.regulations.gov/ document? D=EPA-HQ-OPP-2011-0971-0004

USEPA. 2018. Environmental protection agency 40 CFR Part 180 [EPA-HQOPP2011 -0971; FRL-9977-14] pyrifluquinazon; pesticide tolerances. Fed. Reg. 83: 7. 